\title{
Regulatory T-Cell to Effector T-Cell Ratio Measurement
}

National Cancer Institute

\section{Source}

National Cancer Institute. Regulatory T-Cell to Effector T-Cell Ratio Measurement. NCI Thesaurus. Code C141265.

The determination of the ratio of regulatory T-cells (T regs) compared to effector T-cells present in a sample. 